\title{
Photoluminescence in Er-doped Ge-As-Se chalcogenide thin films
}

\author{
Kunlun Yan, ${ }^{1, *}$ Rongping Wang, ${ }^{1}$ Khu Vu, ${ }^{1}$ Steve Madden, ${ }^{1}$ Kidane Belay, \\ Robert Elliman, ${ }^{2}$ and Barry Luther-Davies ${ }^{1}$ \\ ${ }^{1}$ Centre for Ultrahigh Bandwidth Devices for Optical Systems, Laser Physics Centre, Research School of Physics and \\ Engineering, The Australian National University, Canberra ACT 2600, Australia \\ ${ }^{2}$ Department of Electronic Materials Engineering, Research School of Physics and Engineering, The Australian \\ National University, Canberra ACT 2600, Australia \\ *kunlun.yan@anu.edu.au
}

\begin{abstract}
We report the properties of thermally evaporated $\mathrm{Ge}_{11.5} \mathrm{As}_{24} \mathrm{Se}_{64.5}$ chalcogenide films ion implanted at energies of $2.25 \mathrm{MeV}$ with Erbium at concentrations up to $0.4 \mathrm{~mol} \%$. The effect of post implant annealing on the refractive index of the films and on the ${ }^{4} \mathrm{I}_{13 / 2} \rightarrow{ }^{4} \mathrm{I}_{15 / 2}$ Er transition was studied. Photoluminescence was found to increase significantly and a lifetime of $1.35 \mathrm{~ms}$ was obtained in films annealed at $180^{\circ} \mathrm{C}$. Different apparent lifetimes for the ${ }^{4} \mathrm{I}_{13 / 2} \rightarrow{ }^{4} \mathrm{I}_{15 / 2}$ transition were obtained for $980 \mathrm{~nm}$ and $1470 \mathrm{~nm}$ pumps and the origins of this phenomenon are discussed.
\end{abstract}

(C)2012 Optical Society of America

OCIS codes: (160.5690) Rare-earth-doped materials; (160.4330) Nonlinear optical materials; (310.6860) Thin films, optical properties.

\section{References and links}

1. B. J. Eggleton, B. Luther-Davies, and K. Richardson, "Chalcogenide photonics," Nat. Photonics 5, 141-148 (2011).

2. $\quad \mathrm{K}$. Vu and S. Madden, "Tellurium dioxide Erbium doped planar rib waveguide amplifiers with net gain and 2.8 dB/cm internal gain," Opt. Express 18(18), 19192-19200 (2010).

3. T. Schweizer, D. Brady, and D. W. Hewak, "Fabrication and spectroscopy of erbium doped gallium lanthanum sulphide glass fibres for mid-infrared laser applications," Opt. Express 1(4), 102-107 (1997).

4. D. T. Tonchev, C. J. Haugen, R. G. DeCorby, J. N. McMullin, and S. O. Kasap, "Thermal and photoluminescence properties of $\mathrm{Er}^{3+}$-doped $(\mathrm{GaSe})_{\mathrm{x}}\left(\mathrm{As}_{2} \mathrm{Se}_{3}\right)_{1-\mathrm{x}}$ glasses," J. Non-Cryst. Solids 326-327, 364-368 (2003).

5. T. W. Allen, M. M. Hawkeye, C. J. Haugen, R. G. DeCorby, J. N. McMullin, D. Tonchev, K. Koughia, and S. O. Kasap, "Photoluminescence measurements of Er-doped chalcogenide glasses," J. Vac. Sci. Technol. A 22(3), 921-924 (2004).

6. K. Koughia, M. Munzar, D. Tonchev, C. J. Haugen, R. G. Decorby, J. N. McMullin, and S. O. Kasap, "Photoluminescence in Er-doped Ge-Ga-Se glasses," J. Lumin. 112(1-4), 92-96 (2005).

7. S. Kasap, K. Koughia, G. Soundararajan, and M. G. Brik, "Optical and Photoluminescence Properties of ErbiumDoped Chalcogenide Glasses (GeGaS:Er)," IEEE J. Sel. Top. Quantum Electron. 14(5), 1353-1360 (2008).

8. C. C. Ye, D. W. Hewak, M. Hempstead, B. N. Samson, and D. N. Payne, "Spectral properties of Er ${ }^{3+}$-doped gallium lanthanum sulphide glass," J. Non-Cryst. Solids 208(1-2), 56-63 (1996).

9. D. J. Coleman, P. Golding, T. A. King, and S. D. Jackson, "Spectroscopic and energy-transfer parameters for $\mathrm{Er}^{3+}$-doped and $\mathrm{Er}^{3+}, \mathrm{Pr}^{3+}$-codoped GeGaS glasses," J. Opt. Soc. Am. B 19(9), 1982-1989 (2002).

10. K. Kadono, T. Yazawa, S. Jiang, J. Porque, B.-C. Hwang, and N. Peyghambarian, "Rate equation analysis and energy transfer of $\mathrm{Er}^{3+}$-doped $\mathrm{Ga}_{2} \mathrm{~S}_{3}-\mathrm{GeS}_{2}-\mathrm{La}_{2} \mathrm{~S}_{3}$ glasses," J. Non-Cryst. Solids 331(1-3), 79-90 (2003).

11. S. J. Madden, D. Y. Choi, D. A. Bulla, A. V. Rode, B. Luther-Davies, V. G. Ta'eed, M. D. Pelusi, and B. J. Eggleton, "Long, low loss etched $\mathrm{As}_{2} \mathrm{~S}_{3}$ chalcogenide waveguides for all-optical signal regeneration," Opt. Express 15(22), 14414-14421 (2007).

12. X. Gai, S. Madden, D. Y. Choi, D. Bulla, and B. Luther-Davies, "Dispersion engineered $\mathrm{Ge}_{11.5} \mathrm{As}_{24} \mathrm{Se}_{64.5}$ nanowires with a nonlinear parameter of $136 \mathrm{~W}^{-1} \mathrm{~m}^{-1}$ at $1550 \mathrm{~nm}$," Opt. Express 18(18), 18866-18874 (2010).

13. X. Gai, D.-Y. Choi, S. Madden, and B. Luther-Davies, "Polarization-independent chalcogenide glass nanowires with anomalous dispersion for all-optical processing," Opt. Express 20(12), 13513-13521 (2012).

14. S. Q. Gu, Q. Xu, E. E. Reuter, J. T. Verdeyen, and S. G. Bishop, "Photoluminescence and excitation spectroscopy in Er:As $\mathrm{S}_{3}$ glass," in Lasers and Electro-Optics Society Annual Meeting, 1993, LEOS '93 Conference Proceedings, IEEE (IEEE, 1993), pp. 206-207. 
15. S. Q. Gu, S. Ramachandran, E. E. Reuter, D. A. Turnbull, J. T. Verdeyen, and S. G. Bishop, "Novel broad-band excitation of $\mathrm{Er}^{3+}$ luminescence in chalcogenide glasses," Appl. Phys. Lett. 66(6), 670-672 (1995).

16. V. Lyubin, M. Klebanov, B. Sfez, and B. Ashkinadze, "Photoluminescence and photodarkening effect in erbiumdoped chalcogenide glassy films," Mater. Lett. 58(11), 1706-1708 (2004).

17. C. Vigreux-Bercovici, A. Pradel, A. Fuchs, and J. Fick, "Effect of annealing on the photoluminescence in sputtered films of Er-doped chalcogenide glasses," Phys. Chem. Glasses-B 47(2), 162-166 (2006).

18. J. Fick, É. J. Knystautas, A. Villeneuve, F. Schiettekatte, S. Roorda, and K. A. Richardson, "High photoluminescence in Erbium-doped chalcogenide thin films," J. Non-Cryst. Solids 272(2-3), 200-208 (2000).

19. Z. G. Ivanova, K. Koughia, D. Tonchev, J. C. Pivin, and S. O. Kasap, "Photoluminescence in Er-implanted amorphous Ge-S-Ga thin films," J. Optoelectron. Adv. Mater. 7, 1271-1276 (2005).

20. R. P. Wang, D. Bulla, A. Smith, T. Wang, and B. Luther-Davies, "Structure and physical properties of $\mathrm{Ge}_{\mathrm{x}} \mathrm{As}_{\mathrm{y}} \mathrm{Se}_{1-\mathrm{x}-\mathrm{y}}$ glasses with the same mean coordination number of 2.5," J. Appl. Phys. 109(2), 023517 (2011)

21. D. A. P. Bulla, R. P. Wang, A. Prasad, A. V. Rode, S. J. Madden, and B. Luther-Davies, "On the properties and stability of thermally evaporated Ge-As-Se thin films,” Appl. Phys., A Mater. Sci. Process. 96(3), 615-625 (2009).

22. A. Prasad, C. J. Zha, R. P. Wang, A. Smith, S. Madden, and B. Luther-Davies, "Properties of $\mathrm{Ge}_{\mathrm{x}} \mathrm{As}_{\mathrm{y}} \mathrm{Se}_{1-\mathrm{x}-\mathrm{y}}$ glasses for all-optical signal processing," Opt. Express 16(4), 2804-2815 (2008).

23. Z. G. Ivanova, V. S. Vassilev, E. Cernoskova, and Z. Cernosek, "Physicochemical, structural and fluorescence properties of Er-doped Ge-S-Ga glasses," J. Phys. Chem. Solids 64(1), 107-110 (2003).

24. P. Tronc, M. Bensoussan, A. Brenac, G. Errandonea, and C. Sebenne, "Raman-Scattering and Local Order in $\mathrm{Ge}_{\mathrm{X}} \mathrm{Se}_{1-\mathrm{X}}$ Glasses for $1 / 3 \leq \mathrm{X} \leq 1 / 2$," J. Phys. 38(12), 1493-1498 (1977).

25. S. Mamedov, D. G. Georgiev, T. Qu, and P. Boolchand, "Evidence for nanoscale phase separation of stressedrigid glasses," J. Phys. Condens. Matter 15(31), S2397-S2411 (2003).

\section{Introduction}

Chalcogenide glasses (ChGs) have many important applications in mid-infrared science, nonlinear optics and optical signal processing [1]. The chalcogenides are also potentially very good hosts for rare earth dopants such as Erbium, Holmium and Thulium and could be used to create lasers and optical amplifiers operating in the near- and mid-infrared. There are some major differences between rare-earth doped $\mathrm{ChGs}$ and the more extensively studied rare earth doped silicate glasses. These include lower phonon energy; the possibility of obtaining high dopant concentrations; and relatively high peak emission cross-sections. The low phonon energy of ChGs drastically reduces multi-phonon processes such as multi-phonon relaxation (MPR) or phonon-assisted parasitic transitions (types of up-conversion and cross-relaxation or excited state absorption processes). This enables a whole range of transitions from the visible to the MIR to be exploited in ChGs that are not accessible in higher phonon energy hosts. As a result, investigating the properties of rare earth doped chalcogenide films is an important step towards realizing laser applications.

There are essentially two ways to fabricate rare-earth doped planar waveguides on route to waveguide lasers and amplifiers. The first is to make rare earth doped bulk glasses using standard melt-quenching methods, and then fabricate a thin waveguide film from that glass via physical vapour deposition processes such as thermal evaporation, sputtering, or laser ablation. A 2-D waveguide then has to be etched into the thin film. The second approach is to ion-implant the rare earths selectively into the fully fabricated waveguide. This has the advantage of leveraging proven fabrication routes and easy integration of active and passive sections. Furthermore, the approach avoids the need to etch erbium doped glasses which is difficult because most Er compounds formed during plasma etching are non-volatile and, hence, cause micro-masking which results in a very rough etched surface [2]. So far both of these approaches have been investigated. Erbium has probably been the most studied of the rare earth dopants as it is very well understood in a variety of hosts and it has important applications in telecommunications.

There have now been many reports of Erbium doped chalcogenide glasses and a smaller amount of work on thin films and waveguides. A particular focus has been on chalcogenide hosts containing Ga, such as GaLaS (GLS), GeGaS and GeGaSe [3-10] since these has been shown to accept very high Er concentrations without clustering. For example, Schweizer et al. [3] studied the properties of Er doped GLS glass system for mid infrared applications. 
Tonchev et al. [4], reported a PL lifetime around $1.5-2 \mathrm{~ms}$ with $975 \mathrm{~nm}$ pumping in $\left(\mathrm{As}_{2} \mathrm{Se}_{3}\right)_{1-}$ ${ }_{x}(\mathrm{GaSe})_{\mathrm{x}}$ (with Ga from 0 to $5 \%$ ) bulk glass doped with $\mathrm{Er}_{2} \mathrm{~S}_{3}\left(1 \% \mathrm{Er}^{3+}\right)$. They found that the PL lifetime increased linearly with Ga concentration from about $1.5 \mathrm{~ms}$ to $2 \mathrm{~ms}$ with the addition of Ga up to 5\%. Allen et al. [5] studied the photoluminescence characteristics of a series of Er-doped ChGs and found that whilst all the Er doped ChGs samples exhibited lifetimes in the $1-4 \mathrm{~ms}$ range, GaGeAsSe had the shortest lifetimes of $1-1.5 \mathrm{~ms}$ for $980 \mathrm{~nm}$ pumping, whilst GaGeSe and $\mathrm{GaGeS}$ samples had the highest values of 2-4ms. A strong correlation between the $\mathrm{Er}$ and $\mathrm{Ga}$ concentrations and the properties of Er-doped $\mathrm{Ge}-\mathrm{Ga}-\mathrm{Se}$ glasses was found in [6]. Kasap et al. [7] examined the optical and photoluminescence properties of $\mathrm{Er}^{3+}$-doped $\mathrm{GeGaS}$ glasses of near stoichiometric compositions $\left(\mathrm{Ge}_{28} \mathrm{Ga}_{6.2} \mathrm{~S}_{65.3}: \mathrm{Er}_{0.5}\right)$ and calculated a lifetime around $2.6 \mathrm{~ms}$ using the Judd-Ofelt theory. However, Ga-containing bulk glasses pose significant problems during thin film deposition required to make waveguides. In particular, upon melting these glasses tend to phase separate into a non-volatile $\mathrm{Ga}-\mathrm{S}(\mathrm{Se})$ phase rendering conventional PVD processes useless. As a result, to the best of our knowledge there have been no reports of stable, high quality thin films or waveguides (loss of less than $1 \mathrm{~dB} / \mathrm{cm}$ ) made from Ga-containing chalcogenide glasses.

High quality chalcogenide thin films and waveguides have been reported in other chalcogenide hosts such as $\mathrm{As}_{2} \mathrm{~S}_{3}$, and $\mathrm{Ge}_{11.5} \mathrm{As}_{24} \mathrm{Se}_{64.5}$ [1,11-13]. For example, loss values as low as $0.05 \mathrm{~dB} / \mathrm{cm}$ at $1550 \mathrm{~nm}$ have been measured for $4 \mu \mathrm{m}$ wide $\mathrm{As}_{2} \mathrm{~S}_{3}$ rib waveguides etched into $2.5 \mu \mathrm{m}$ thick films, whilst losses for highly nonlinear dispersion-engineered $\mathrm{As}_{2} \mathrm{~S}_{3}$ waveguides with a nonlinearity, $\gamma, \approx 10 \mathrm{~W}^{-1} \mathrm{~m}^{-1}$ are now as low as $0.3 \mathrm{~dB} / \mathrm{cm}$ [11]. Recently, $\mathrm{Ge}_{11.5} \mathrm{As}_{24} \mathrm{Se}_{64.5}$ nanowires with $\approx 500 \times 630 \mathrm{~nm}$ cross section and extreme nonlinearity of $\gamma=$ $130-150 \mathrm{~W}^{-1} \mathrm{~m}^{-1}$ and moderate losses of $\approx 1.5 \mathrm{~dB} / \mathrm{cm}$ were also reported [1]. These materials have to date been proven to be the most suitable for planar waveguides $[1,12,13]$. However, doping of rare earths into bulk glasses with these compositions is difficult because the absence of Ga means the solubility of the rare earths in bulk glass is very low. It has been shown that the Er solubility in $\mathrm{As}_{2} \mathrm{~S}_{3}$ bulk glass is only 0.1 at.\% [14] while for the ternary $\mathrm{Ge}_{33} \mathrm{As}_{12} \mathrm{Se}_{55}$ glass, Er clustered at concentrations above $0.2 \mathrm{wt} . \%$ [15].

Interestingly, there is strong evidence that some films can incorporate larger amounts of rare earths compared with bulk samples when prepared by co-evaporation. This is most probably due to the fact that films are created in non-equilibrium conditions by condensing a vapour onto a cold substrate. This means that single isolated rare earth atoms are immediately immobilized within the film inhibiting clustering. This contrasts sharply with the situation used to create a bulk glass where the dopant has to be soluble in the molten host. Lyubin et al. [16] reported that co-thermal evaporation of $\mathrm{Er}$ with $\mathrm{As}_{2} \mathrm{~S}_{3}$ produced films with $\mathrm{Er}$ concentration as high as 4 at.\% without any signs of clustering and led to strong PL emission under $\mathrm{Ar}^{+}$laser excitation at $514 \mathrm{~nm}$. Vigreux-Bercovici et al. [17] also reported sputtering of a $3 \% \mathrm{Er}: \mathrm{As}_{2} \mathrm{~S}_{3}$ composite target to produce a thin film that had $1.5 \mu \mathrm{m}$ transition lifetime of $4 \mathrm{~ms}$.

Whilst this is encouraging, the problem of etching rare earth doped films remains and hence it is still attractive to introduce the dopant after waveguide fabrication using ion implantation. In this approach a $\mathrm{ChG}$ host that makes the most stable low loss waveguides can be employed. Fick et al. observed a strong $\mathrm{Er}^{3+}$ emission at $1.54 \mu \mathrm{m}$ from $\mathrm{Er}$ ion implanted $\mathrm{As}_{2} \mathrm{~S}_{3}$ and $\mathrm{As}_{24} \mathrm{~S}_{38} \mathrm{Se}_{38}$ films with the lifetime of $2.3 \mathrm{~ms}$ [18]. In Ivanova's work [19] the PL properties of Ge-S-Ga films ion implanted with relatively low energy $(320 \mathrm{keV})$ ions at different fluences was investigated. They reported that the PL efficiency reduced with increasing Er concentration and that thermal annealing at 230C approximately doubled the PL efficiency at all doses.

Recently, we found that glasses from within the ternary $\mathrm{Ge}_{x} \mathrm{As}_{y} \mathrm{Se}_{100-x-y}$ glass system with mean coordination number $(\mathrm{MCN}) \approx 2.47$, e.g. $\mathrm{Ge}_{11.5} \mathrm{As}_{24} \mathrm{Se}_{64.5}$ are the best glasses in this ternary system for waveguide applications and displays excellent structural stability against thermal or optical annealing [20,21]. Furthermore, this composition displayed close to the 
highest third order nonlinearity of any of the glasses in the Ge-As-Se system, low enough absorption coefficient around $0.05 \mathrm{~dB} / \mathrm{cm}$ at $1550 \mathrm{~nm}$ [22] and can readily be formed to low loss waveguides making it a good choice for all-optical processing. Therefore, in this paper we have investigated the properties of $\mathrm{Ge}_{11.5} \mathrm{As}_{24} \mathrm{Se}_{64.5}$ thin films doped with erbium by ion implantation.

\section{Experiments}

Films of $\mathrm{Ge}_{11.5} \mathrm{As}_{24} \mathrm{Se}_{64.5} 877 \pm 5 \mathrm{~nm}$ thick were prepared by thermal evaporation from bulk glass prepared using the conventional melt-quenching technique from high-purity $(5 \mathrm{~N})$ elements. A Tantalum baffled box was used as the source because this eliminated any line-ofsight between the melt and the substrates and thereby eliminated particulate contamination in the film due to "spitting". The Ta baffled box was heated by a halogen lamp in a water-cooled reflector to the evaporation temperature which was then stabilized using a PID controller reading a thermocouple in the boat. Oxidized $100 \mathrm{~mm}$ diameter $\mathrm{Si}$ wafers were used as substrates placed in a carousel and rotated in planetary motion above the source. Typical boat to substrate distance was $400 \mathrm{~mm}$. More details can be found in [21]. The film linear refractive index (n) and thickness were measured by a spectroscopic reflectometer (SCI FilmTek 4000) using a Tauc-Lorentz model. Raman spectra were measured using a Horiba Jobin Yvon 64000 spectrometer with an 830nm laser as the excitation source. The surface morphology of the films was determined using optical profilometry (Wyko NT9100).

The Er ion implantation was performed using the Australian National University Tandem accelerator. Three pieces of film were ion-implanted with Er ions at an energy of $2.25 \mathrm{MeV}$ with doses of $1.56 \times 10^{15} \mathrm{~cm}^{-2}, 3.1 \times 10^{15} \mathrm{~cm}^{-2}$ and $6.2 \times 10^{15} \mathrm{~cm}^{-2}$, respectively, corresponding to a peak Er concentration of 0.1, 0.2 and $0.4 \mathrm{~mol} \%$. The Er distribution against depth was calculated using SRIM and found to have a Gaussian shape with peak depth at 502nm and FWHM width of $350 \mathrm{~nm}$. This depth was targeted as it allowed high overlap of the optical mode with the implanted ions. The areas that were ion implanted were about $15 \mathrm{~mm} \times 10 \mathrm{~mm}$ for all of the three samples. In addition, the simulation results also indicated that the top of the thin films would be sputtered away to depths of 5, 10 and $20 \mathrm{~nm}$ for low to high doses, respectively.

The as-implanted films were progressively thermally annealed in a high vacuum $\left(\sim 10^{-5} \mathrm{~Pa}\right)$ oven at $180^{\circ} \mathrm{C}$, which is slightly below the measured glass transition temperature $T_{g}=230^{\circ} \mathrm{C}$ of $\mathrm{Ge}_{11.5} \mathrm{As}_{24} \mathrm{Se}_{64.5}$ bulk glasses. Thermal annealing would be expected to reduce the damage to the glass network caused by the high energy $\mathrm{Er}$ ion implantation [18]. The photoluminescence at $1550 \mathrm{~nm}$ was measured using an all-fiber confocal set up with pumps at $1470 \mathrm{~nm}$ and $980 \mathrm{~nm}$ delivered to the edge of the film via a lens tipped fiber [2]. The lensed fiber produced a $2.5 \mu \mathrm{m} 1 / \mathrm{e}^{2}$ diameter spot and was aligned to the edge of the film to couple the $1470 \mathrm{~nm}$ (or $980 \mathrm{~nm}$ ) pump laser which was modulated with $\sim 10 \mathrm{~ms}$ long square pulses. The fluorescence was then coupled back into the fiber and then the $\approx 1550 \mathrm{~nm}$ component extracted and the pump rejected by a chain of three $1470 \mathrm{~nm}$ (or $980 \mathrm{~nm}$ ) $/ 1550 \mathrm{~nm}$ WDMs providing in excess of $90 \mathrm{~dB}$ pump rejection. Detection was accomplished with a connectorised $150 \mu \mathrm{m}$ diameter InGaAs diode and a fast, low noise Signal Recovery Inc. transimpedance amplifier. Data was captured on a PC equipped with a 16 bit analog to digital converter, and custom software enabled arbitrary amounts of trace averaging to remove noise [2]. The rise and fall time of the system was less than $10 \mu$ s allowing very accurate lifetime measurement even for sub-ms lifetimes.

\section{Results and discussions}

All the as-deposited, as-implanted and annealed films showed a smooth surface when measured using a Veeco NT9100 optical profiler with an x100 objective, with RMS roughness below $0.5 \mathrm{~nm}$, indicating that sputtering caused by the high energy implantation and the subsequent thermal annealing had a negligible effect on the surface roughness.

\#172186 - \$15.00 USD Received 10 Jul 2012; revised 7 Aug 2012; accepted 7 Aug 2012; published 20 Aug 2012

(C) 2012 OSA 1 September 2012 / Vol. 2, No. 9 / OPTICAL MATERIALS EXPRESS 1273 
To understand the effect of implant and thermal annealing on the film structure, the normalized Raman spectra of the films were measured and these are shown in Fig. 1. The spectra contain a strong band at $230 \mathrm{~cm}^{-1}$ which is mainly due to the vibration of $\mathrm{AsSe}_{3 / 2}$ pyramidal units, and another at about $195 \mathrm{~cm}^{-1}$ which is associated with the vibration mode of corner-sharing of $\mathrm{GeSe}_{4 / 2}$ tetrahedra [23]. These two features remain unchanged before and after thermal annealing, indicating the host material is stable, and implantation and annealing have not resulted in detectable changes in the chemical bonding. The growth of features at $150 \mathrm{~cm}^{-1}$ and $175 \mathrm{~cm}^{-1}$ after 10 hours of annealing has occasionally been seen in un-doped films of $\mathrm{Ge}_{11.5} \mathrm{As}_{24} \mathrm{Se}_{64.5}$ and is thought to be a result of nanoscale phase separation and the appearance of a GeSe or $\mathrm{As}_{4} \mathrm{Se}_{4}$ phase [24,25]. It is therefore not considered to be due to the erbium doping or ion implant processes.

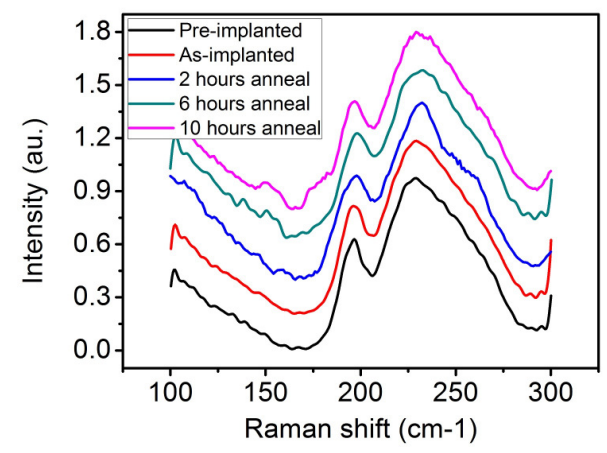

Fig. 1. Raman spectra of $0.4 \mathrm{~mol} \%$ concentration film with different anneal times.

The effect of the implant and annealing is more evident from the thickness and refractive index. These change as a function of annealing time as shown in Fig. 2. The 877nm-thick asdeposited film was reduced in thickness to $871.5,857$ and $829 \mathrm{~nm}$ respectively for $0.1,0.2$ and $0.4 \mathrm{~mol} \% \mathrm{Er}$ ion implantation. The changes in the thickness of 5.5, 20 and $48 \mathrm{~nm}$ are significantly larger than the estimates due to sputtering of 5, 10 and $20 \mathrm{~nm}$ which could either mean that the high ion-implantation dose compressed the films, or alternatively that the sputter yield was underestimated.

After thermal annealing for 10 hours, the thicknesses stabilized at 849,837 and $812 \mathrm{~nm}$, demonstrating that the films shrink further during annealing and end up 2.6, 2.4, and 2.1\% thinner relative to the post implant thicknesses. The refractive index prior to implantation was $2.662 \pm 0.001$ at $1550 \mathrm{~nm}$. Implantation appears to result in a measurable drop in refractive index whilst annealing then causes the refractive indices to increase stabilizing at 2.662, 2.665 and 2.673 for the $0.1,0.2$ and $0.4 \mathrm{~mol} \%$ ion implanted films, respectively. Overall these results suggest that implantation damages the glass network, in fact causes it to swell, but that upon annealing that damage is largely eliminated. In the case of the lowest implant dose the index retuned to the value for the un-implanted film. A decrease in thickness accompanied by an increase in index is consistent with a reduction of defects in the glass network essentially annealing away the damage caused by the implant. At the highest implant dose the index stabilized about 0.01 above the original glass film after annealing. Assuming that the density changes in proportion to the change in thickness, the Lorentz-Lorenz relationship would predict a much larger change in index than was observed. This suggests that a significant reduction in average polarizability of the film occurred during the incorporation of the Er. 

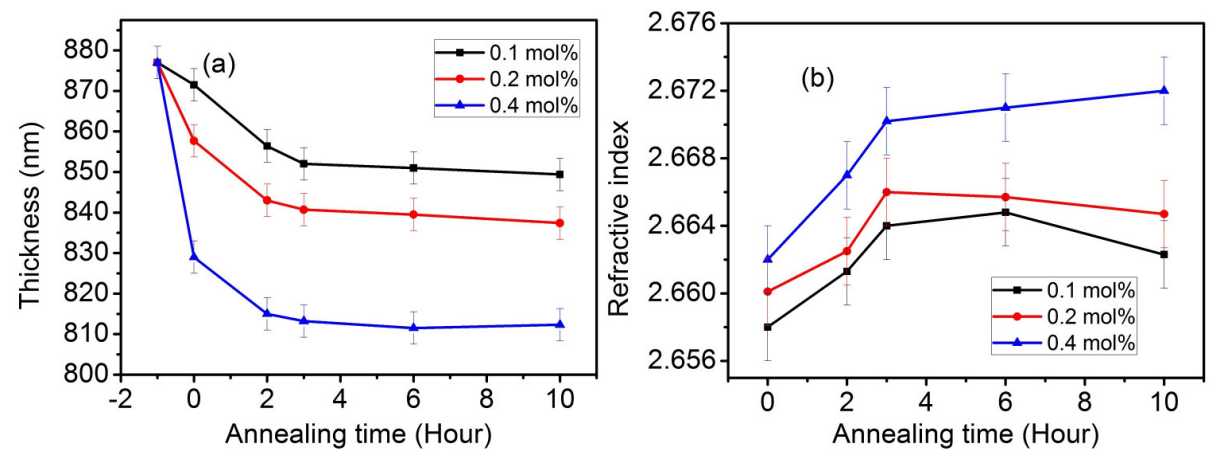

Fig. 2. Thicknesses (a) and linear refractive indices at $1550 \mathrm{~nm}$ wavelength. Note: -1 hour means before implantation. (b) The lines are guides to the eye.

The normalized PL spectra obtained using the $1470 \mathrm{~nm}$ pump for the films after annealing for 10 hours are shown in Fig. 3(a) and the spectra for the $0.4 \mathrm{~mol} \%$ doped film before and after 2 hours annealing in Fig. 3(b). Note that in both these spectra the abrupt drop in intensity at $1515 \mathrm{~nm}$ was due to the WDM filters. The PL spectra in Fig. 3(a) for the different concentrations were indistinguishable in terms of PL line shape and the peak positions. The peak emission lay at $1539 \mathrm{~nm}$, which is red shifted relative, for example, to oxide glass hosts and the FWHM bandwidth was $38 \mathrm{~nm}$. Due to the drop in quality of the cleaved edge due to handling during the annealing process, there was some variability $( \pm 15 \%)$ in the measurements in the PL intensity at the different annealing times and for different doping concentrations. However, it was apparent that the PL intensity increased with the doping concentration but less than linearly - the signal after 10 hours annealing for $0.4 \mathrm{~mol} \%$ doping concentration being only three times that for $0.1 \mathrm{~mol} \%$ indicating that reduction in the PL efficiency occurred as the dose increased similar to that reported in [19]. The PL intensity increased substantially (by around a factor of 3-4) as a result of annealing as illustrated by the comparison between spectra for the as-implanted sample and that annealed for 2 hours in Fig. 3(b). Such an increase in the PL signal is normally described as resulting from "activation" of the Er ions, although to our knowledge the chemical environment that optimizes PL is not known for these glasses. However, it is generally accepted that the damage caused to the glass network by implantation can be reduced by thermal annealing allowing more of the Er ions to find active sites thereby increasing the PL intensity [18].
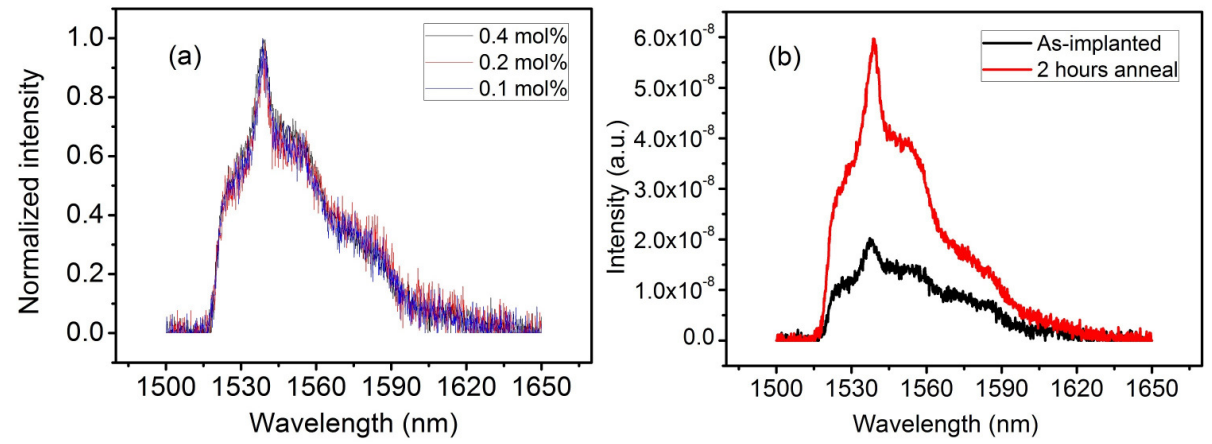

Fig. 3. Room temperature normalized PL obtained from the 10 hours annealing films with different concentrations (a) and room temperature PL of $0.4 \mathrm{~mol} \%$ doped film before and after 2 hours annealing (b). 
PL lifetime is an important parameter to evaluate the performance of the Er-doped ChG films. Figure 4(a) shows the luminescence decay curve for the 0.4 mol\% doped film as implanted and after 10 hours of annealing when pumped at 1470nm. Figure 4(b) shows the observed PL lifetimes as a function of the annealing time for $1470 \mathrm{~nm}$ pumping as a function of implant dose. And here the first e-folding time was defined as the lifetime. Before annealing the lifetimes of the $0.1,0.2$ and $0.4 \mathrm{~mol} \%$ doped films were $1.16,1.1$ and $1.04 \mathrm{~ms}$, respectively. After 3 hours annealing all the lifetimes increased to $1.35 \mathrm{~ms}$, and remained almost constant with increasing annealing time. In the as-implanted samples defects within the glass network act as local phonon sources which couple to the Er ions reducing their lifetime. Thermal annealing at the temperature slightly below $T g$ of the host glass can reduce the number of these defects increasing the lifetime [18]. The results indicate that the lifetime does not depend significantly on the Er concentration which is expected when clustering is avoided through implantation.
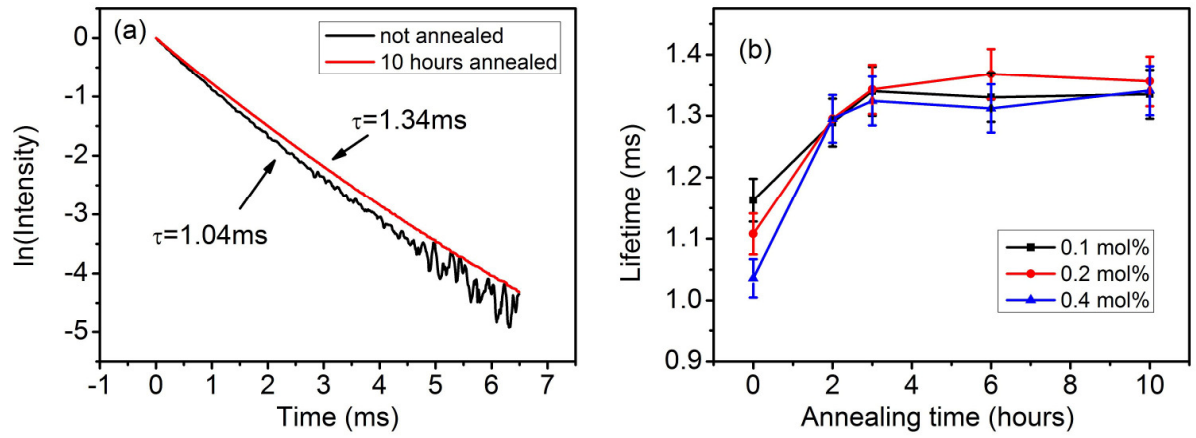

Fig. 4. Plot of decay curve for the not annealed and 10 hours annealed samples (a) and PL lifetimes versus the annealing time (b).

Chalcogenides are well known for their low maximum phonon energy, and therefore for a very low multiphonon relaxation rate for the ${ }^{4} \mathrm{I}_{11 / 2} \rightarrow{ }^{4} \mathrm{I}_{13 / 2}$ transition. We found, as a result, that if a 980nm pump was used the apparent lifetime of the ${ }^{4} \mathrm{I}_{13 / 2} \rightarrow{ }^{4} \mathrm{I}_{15 / 2}$ transition was longer $(1.43 \mathrm{~ms})$ than those obtained by direct pumping at $1470 \mathrm{~nm}(1.34 \mathrm{~ms})$. Figure 5 shows normalized decay curves for signal at $1.54 \mu \mathrm{m}$ when pumped at $980 \mathrm{~nm}$ and at $1470 \mathrm{~nm}$. A nonlinear tail with a much longer decay constant is evident in the case of the $980 \mathrm{~nm}$ pump. The difference is most likely related to a slower relaxation from the ${ }^{4} \mathrm{I}_{11 / 2}$ level to the ${ }^{4} \mathrm{I}_{15 / 2}$ level and down cascade processes from ions in higher levels due to ion-ion interactions such as co-operative upconversion and excited state absorption (ESA) from the ${ }^{4} \mathrm{I}_{11 / 2}$ level. This effect has been confirmed by a number of Judd-Ofelt analyses of Er doped chalcogenide glasses [8-10]. For instance, Ye et al. [8] studied the PL spectrum and PL lifetime of GLS and showed the decay lifetime of the ${ }^{4} \mathrm{I}_{11 / 2}$ level was $1.23 \mathrm{~ms}$ compared to a lifetime of $2.3 \mathrm{~ms}$ for the ${ }^{4} \mathrm{I}_{13 / 2}$. At the same time, the strength of the PL signal at $1.54 \mu \mathrm{m}$ was significantly lower when pumped at $980 \mathrm{~nm}$ compared with $1470 \mathrm{~nm}$ pumping. This is because the efficiency of the ${ }^{4} \mathrm{I}_{11 / 2}$ to ${ }^{4} \mathrm{I}_{13 / 2}$ transition in chalcogenide is reduced due to the low multiphonon relaxation rate from ${ }^{4} \mathrm{I}_{11 / 2}$ to ${ }^{4} \mathrm{I}_{13 / 2}$. For instance, the percentage of ions in level ${ }^{4} \mathrm{I}_{11 / 2}$ that will decay down to ${ }^{4} \mathrm{I}_{13 / 2}$ via both radiative and non-radiative routes are $20 \%$ in GaLaS [8], 25\% in GaGeS [9]. Because of the thin film nature of the sample, it is not possible to perform Judd-Ofelt analysis on our Er implanted GeAsSe samples but it can be assumed to be similar to these reported values. Bulk samples of GeAsSe doped with 1 at.\% Erbium were also prepared to determine the host glass performance but there was no photoluminescence most likely due to clustering of the Er. 


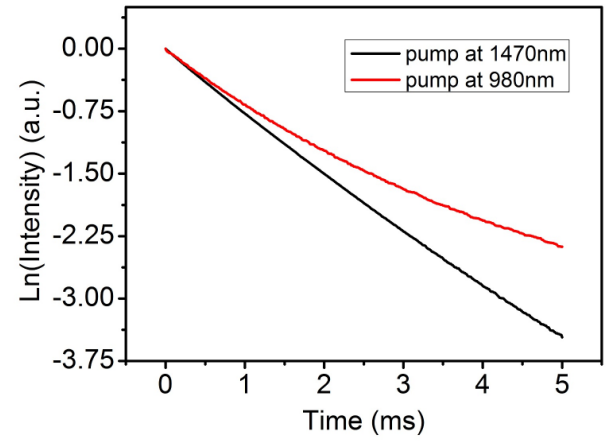

Fig. 5. Decay curve for 10 hours annealed samples with different pump lasers.

\section{Conclusion}

Er ions were implanted into $\mathrm{Ge}_{11.5} \mathrm{As}_{24} \mathrm{Se}_{64.5}$ thin films with different doses, and subsequently thermally annealed at $180^{\circ} \mathrm{C}$ for times up to $10 \mathrm{~h}$. The optical and photoluminescence properties of the annealed films were measured. The results indicated that the thickness and refractive index of the films can be stabilized with 3 hours of thermal annealing. The emission around $1.54 \mu \mathrm{m}$ arising from the ${ }^{4} \mathrm{I}_{13 / 2} \rightarrow{ }^{4} \mathrm{I}_{15 / 2}$ transition was observed and a lifetime of $1.35 \mathrm{~ms}$ was obtained. We have found that thermal annealing is an effective way to enhance the PL intensity and increase the lifetime. These results indicate that Er doped $\mathrm{Ge}_{11.5} \mathrm{As}_{24} \mathrm{Se}_{64.5}$ could be a good material for a waveguide optical amplifier and laser at telecom wavelengths.

\section{Acknowledgments}

This research was conducted by the Australian Research Council Centre of Excellence for Ultrahigh bandwidth Devices for Optical Systems (project number CE110001018).

\#172186 - \$15.00 USD Received 10 Jul 2012; revised 7 Aug 2012; accepted 7 Aug 2012; published 20 Aug 2012

(C) 2012 OSA 1 September 2012 / Vol. 2, No. 9 / OPTICAL MATERIALS EXPRESS 1277 